\title{
Efficacy and safety of tacrolimus in induction therapy of patients with lupus nephritis
}

This article was published in the following Dove Medical Press journal:

Drug Design, Development and Therapy

\author{
Tianbiao Zhou' \\ Shujun Lin' \\ Shen Yang ${ }^{2}$ \\ Wenshan Lin' \\ 'Department of Nephrology, \\ The Second Affiliated Hospital, \\ Shantou University Medical College, \\ Shantou 5I504I, China; ${ }^{2}$ Department \\ of Nephrology, Huadu District \\ People's Hospital of Guangzhou, \\ Southern Medical University, \\ Guangzhou 510800, China
}

Background: The purpose of this study was to detect the efficacy and safety of tacrolimus (TAC) in induction therapy of patients with lupus nephritis.

Methods: Associated studies were extracted from the PubMed and the Cochrane Library on July 10, 2018, and applicable investigations were pooled and analyzed by meta-analysis. Data on complete remission (CR), total remission (TR; complete plus partial remission), proteinuria levels, urine erythrocyte number, albumin, glomerular filtration rate, negative rate of ds-DNA, $\mathrm{C}_{3}$ levels, $\mathrm{C}_{4}$ levels, systemic lupus erythematosus disease activity index (SLE-DAI), etc, were extracted and pooled using RevMan 5.3.

Results: In the therapeutic regimen of TAC + glucocorticoids (GC) vs cyclophosphamide $(\mathrm{CYC})+\mathrm{GC}$, the results indicated that the TAC group had high values of CR, TR, albumin, and negative rate of ds-DNA, and low values of proteinuria levels and SLE-DAI when compared with those in CYC group (all $P<0.05$ ). In the therapeutic regimen comprising TAC + GC vs mycophenolate mofetil $(\mathrm{MMF})+\mathrm{GC}$, the results indicated that the difference of $\mathrm{CR}$, TR, proteinuria levels, and albumin between TAC group and MMF group were not significant (all $P>0.05$ ). In the therapeutic regimen comprising TAC $+\mathrm{MMF}+\mathrm{GC}$ vs $\mathrm{CYC}+\mathrm{GC}$, multitarget therapy group showed higher values of $\mathrm{CR}$, TR, urinary protein decline, and rise of serum albumin when compared with CYC group (all $P<0.05$ ).

Conclusion: TAC is an effective and safe agent in induction therapy of patients with lupus nephritis.

Keywords: tacrolimus, lupus nephritis, complete remission, CR, total remission, TR, meta-analysis

\section{Introduction}

Systemic lupus erythematosus (SLE) is a chronic autoimmune disease in which autoantibodies target a variety of self-antigens, ${ }^{1}$ and persistent disease activity is associated with increased morbidity and mortality. Immune activation of T-helper cells and $\mathrm{B}$ cells takes part in the pathogenesis, and endogenous antigens are generated.,.$^{2,3}$ To clear the antigens, the immune system produces the autoantibodies, which induces tissue inflammation and multiorgan inflammation, especially in kidney. ${ }^{4,5}$ Lupus nephritis is one of the most serious complications of SLE and occurs in up to $60 \%$ of patients worldwide; among them, 50\%-80\% are pediatric-onset SLE cases. ${ }^{6-9}$ Without drug intervention, long-term inflammation may cause irreversible damage to kidney and may cause chronic kidney disease, which subsequently develops into end-stage renal disease.

Traditional therapy for SLE involved the combination of glucocorticoids (GC) with cyclophosphamide (CYC), which was found to be effective in improving long-term prognosis. However, its application was limited because of severe adverse effects, including
Correspondence: Tianbiao Zhou Department of Nephrology, The Second Affiliated Hospital, Shantou University Medical College, No 69 Dongsha Road, Shantou 5I504I, China Email zhoutb@aliyun.com $\mathrm{BY}$
hereby accept the Terms. Non-commercial uses of the work are permitted without any further permission from Dove Medical Press Limited, provided the work is properly attributed. For permission for commercial use of this work, please see paragraphs 4.2 and 5 of our Terms (https://www.dovepress.com/terms.php). 
sepsis, amenorrhea, hemorrhagic cystitis, malignancy, and so on. New immunosuppressants such as mycophenolate mofetil (MMF), cyclosporine, and tacrolimus (TAC) are needed to reverse the situation. Also, azathioprine (AZA) or MMF is used for maintenance therapy because of their safety and function of inducing remission of kidney function. ${ }^{4,10}$ Though various immunosuppressive drugs play a role in the battle with SLE, few randomized controlled clinical trials were conducted to make comparisons among the available treatments for lupus nephritis or interpret the efficacy and safety of TAC. ${ }^{11}$

TAC has a long history in kidney transplantation. As a calcineurin inhibitor, it hinders T-cell activation by inhibiting the calcium/calmodulin-dependent phosphatase calcineurin and combining with FKBP12., ${ }^{5,12}$ It also results in the decrease of IL-2, IL-4, IL-5, IFN- $\gamma$, and TNF- $\alpha . .^{9,13}$ In the past years, some clinical trials were conducted to explore whether the use of TAC can lead to a better remission of lupus nephritis.

The update of immunosuppressive drugs helps not only in increasing the long-term survival rate of the patients but also in decreasing the associated side effects of corticosteroids. ${ }^{12,14}$ Thus, we performed a systematic review and meta-analyses to assess the efficacy and safety of TAC in induction therapy of patients with lupus nephritis.

\section{Materials and methods}

\section{Search strategy}

Systematic searches were performed in the Cochrane Library and PubMed without language limitations from when the database is created to July 10, 2018 using the search terms: (tacrolimus OR FK506 OR TAC) AND (systemic lupus erythematosus OR systemic lupus erythematous OR lupus nephritis OR lupus glomerulonephritis OR lupus nephropathy). We also checked the references cited in the recruited articles for additional reports.

\section{Inclusion and exclusion criteria Inclusion criteria}

The inclusion criteria for this study were as follows: 1) study type: randomized controlled trials, open-label prospective studies, case-control studies, observational studies, and cohort studies; 2) object of the study: all patients regardless of race who met the diagnostic criteria only for lupus nephritis; 3) interventions: TAC for treatment; and 4) baseline information: TAC was compared with placebo or other drugs.

\section{Exclusion criteria}

Exclusion criteria for the study were as follows: 1) case reports, reviews, letters, systematic reviews, and meta-analysis;
2) studies that did not include different therapeutic regimens; and 3 ) the diagnostic criteria were not clear.

\section{Outcome measures}

Efficacy of TAC: complete remission (CR), total remission (TR; total CR plus partial remission [PR]), proteinuria levels, urine erythrocyte number, albumin, glomerular filtration rate (GFR), negative rate of ds-DNA, $\mathrm{C}_{3}$ levels, $\mathrm{C}_{4}$ levels, systemic lupus erythematosus disease activity index (SLE-DAI), urinary protein decline, and rise of serum albumin.

Safety of TAC: gastrointestinal syndrome, leucopenia, hypertension, hyperglycemia, infection, pneumonia, upper respiratory infection, urinary tract infection, herpes zoster or varicella, alopecia, irregular menstruation, increase in blood creatinine levels, and liver function disorder.

\section{Data collection}

According to the predetermined inclusion criteria, two reviewers scanned the titles and abstracts of the included studies or read the full text to screen for possible relevant literature. Discordant opinions were discussed and resolved by other reviewers. Only randomized controlled trials, randomized cross-over studies, and prospective studies that were related to TAC treatment were included in the analysis.

\section{Statistical analysis}

The data were extracted from the included literature and Review Manager version 5.3 software was used to pool the results. Heterogeneity was quantified using $I^{2}$ statistics and explored for all the meta-analyses. On the basis of the test of heterogeneity, when the $P$-value $\geq 0.1$, a fixed-effects model was used. Otherwise, the results were pooled using a random-effects model. Continuous data were expressed using weighted mean differences (WMDs), and binary data were expressed using the OR. 95\% CIs were calculated for the included studies with the Mantel-Haenszel $(\mathrm{M}-\mathrm{H})$ method. A $P$-value $<0.05$ was regarded as statistical significance.

\section{Results \\ Search results}

In this meta-analysis, 13 clinical trials ${ }^{15-27}$ were related to TAC for lupus nephritis (Table 1). There were 12 randomized controlled studies and one ${ }^{21}$ prospective study (Table 1).

\section{Study of the therapeutic regimen of TAC + GC vs CYC + GC}

Seven studies ${ }^{16-18,21,22,24,25}$ were included into the metaanalysis to assess the efficacy of TAC in patients with lupus nephritis. In the therapeutic regimen of $\mathrm{TAC}+\mathrm{GC}$ 


\begin{tabular}{|c|c|c|c|c|}
\hline 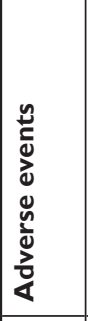 & 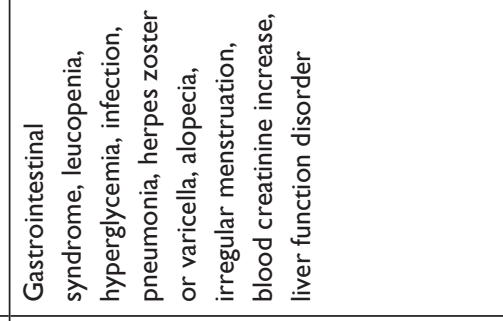 & 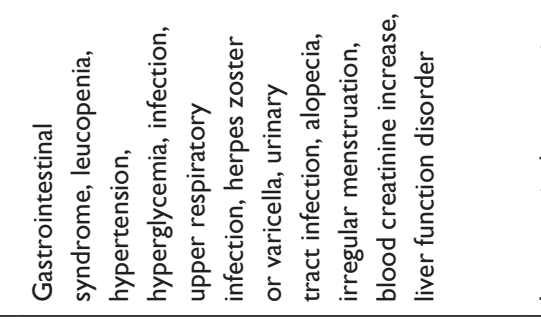 & 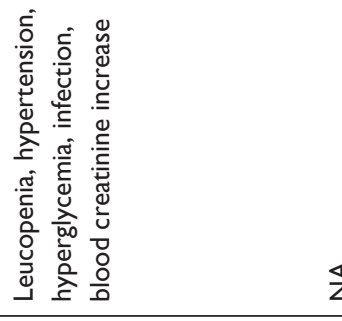 & ¿ \\
\hline 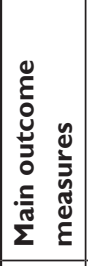 & 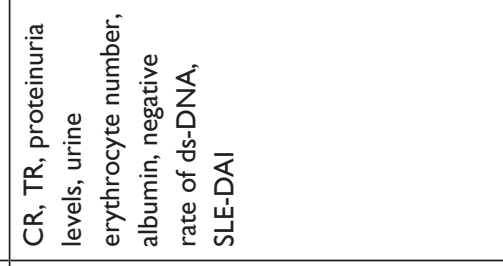 & 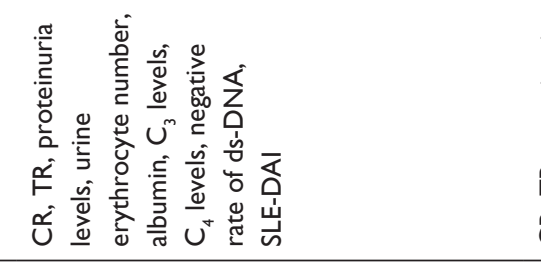 & 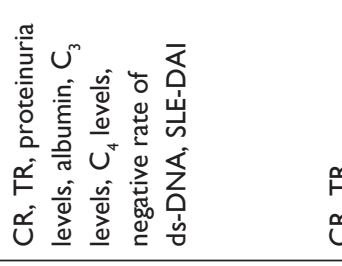 & $\begin{array}{l}\stackrel{\alpha}{⺊} \\
\stackrel{\sim}{U}\end{array}$ \\
\hline 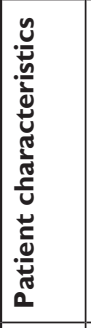 & 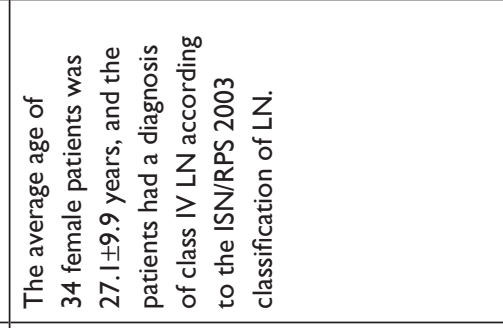 & 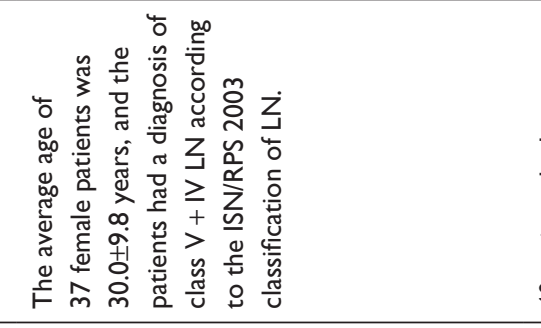 & 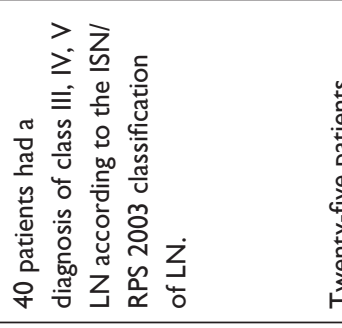 & 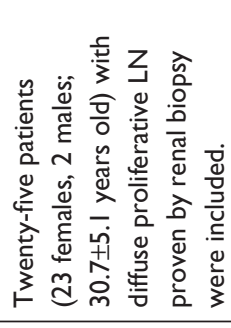 \\
\hline 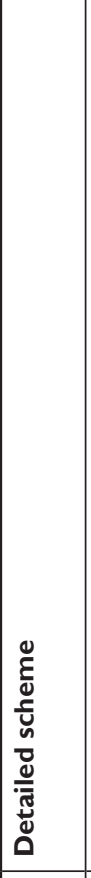 & 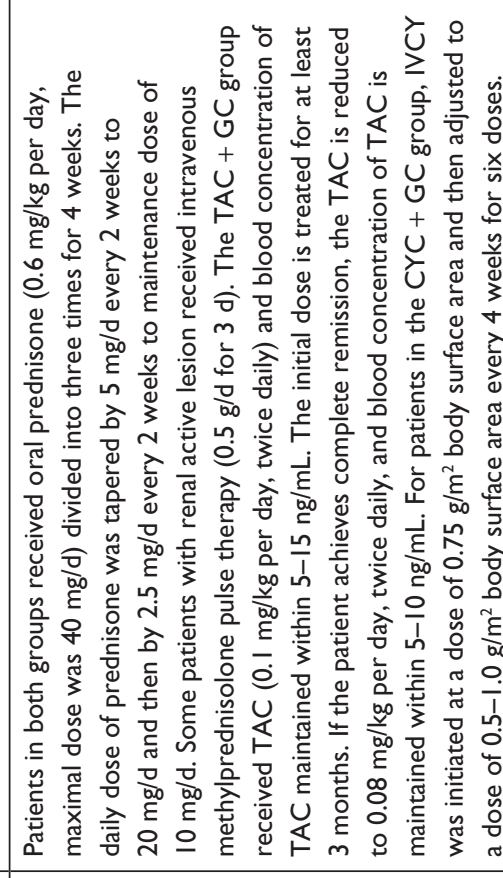 & 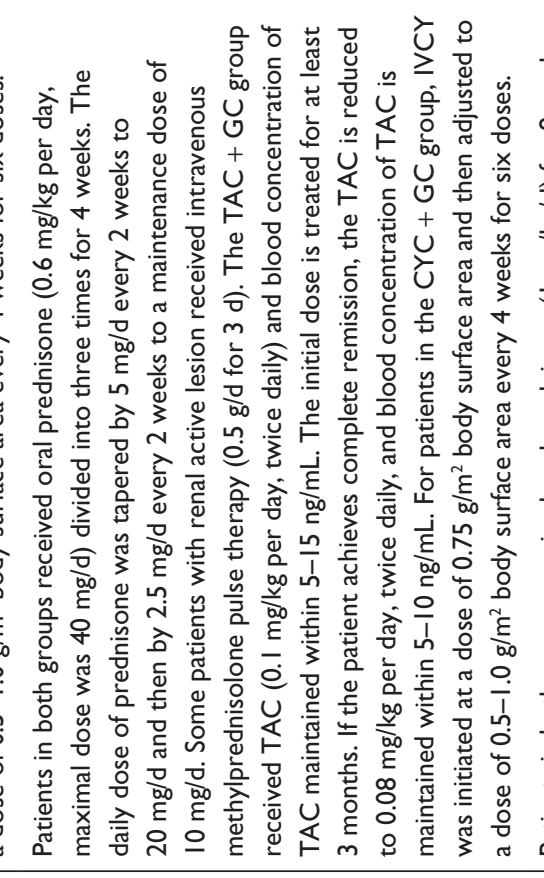 & 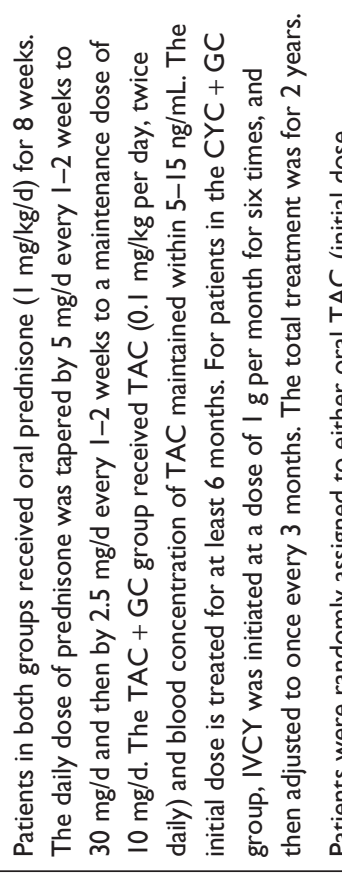 & 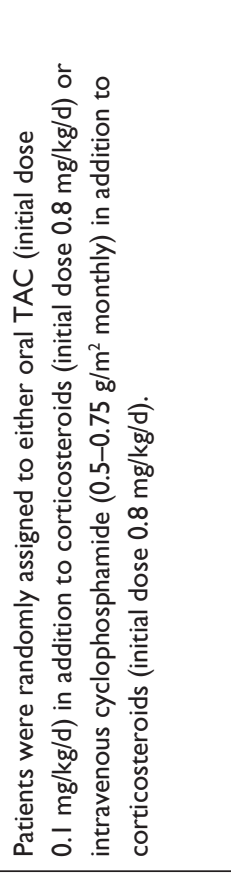 \\
\hline 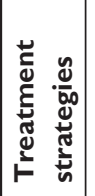 & 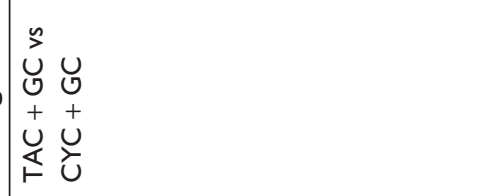 & 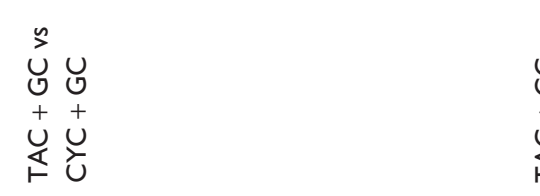 & 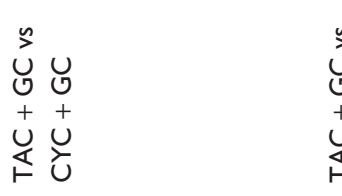 & 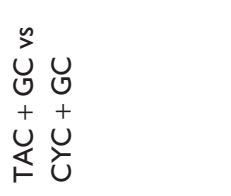 \\
\hline 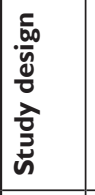 & 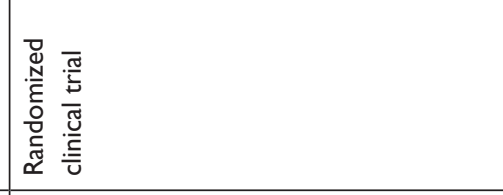 & 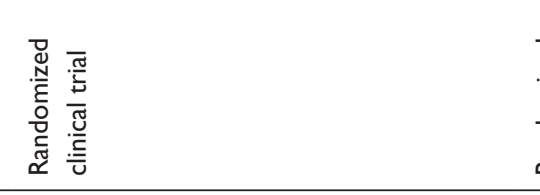 & 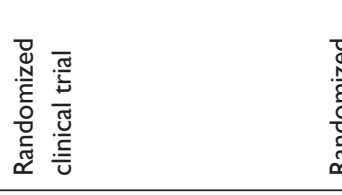 & 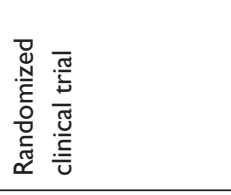 \\
\hline 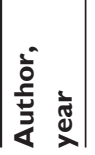 & 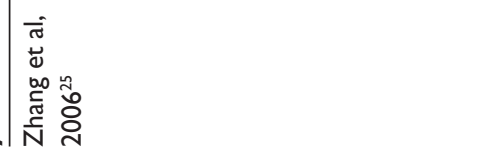 & 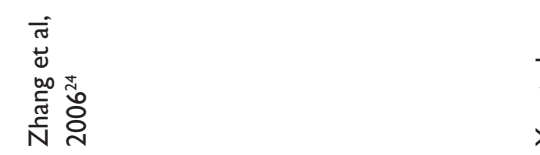 & 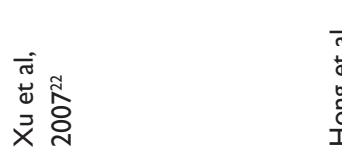 & 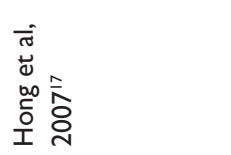 \\
\hline
\end{tabular}




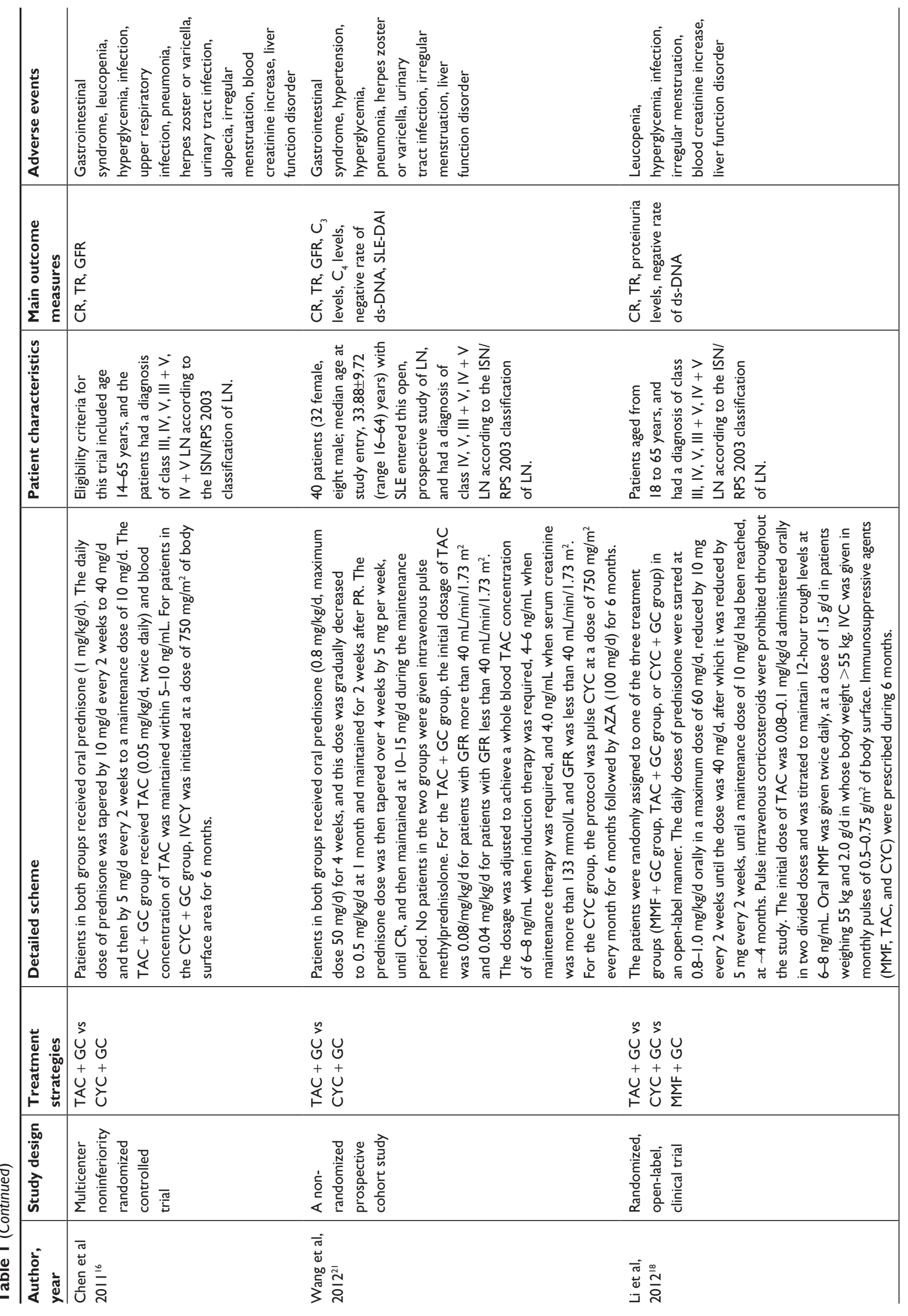




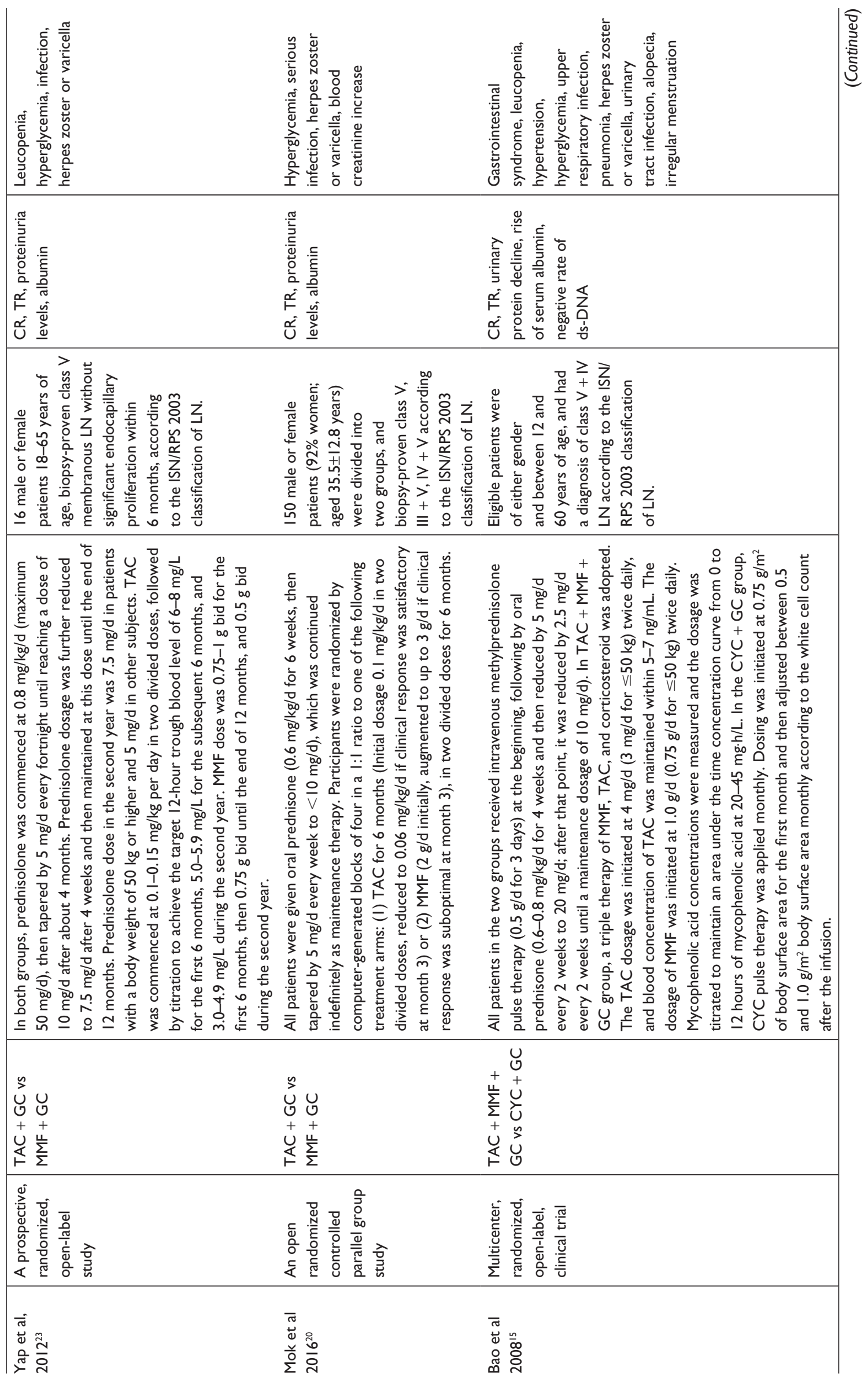




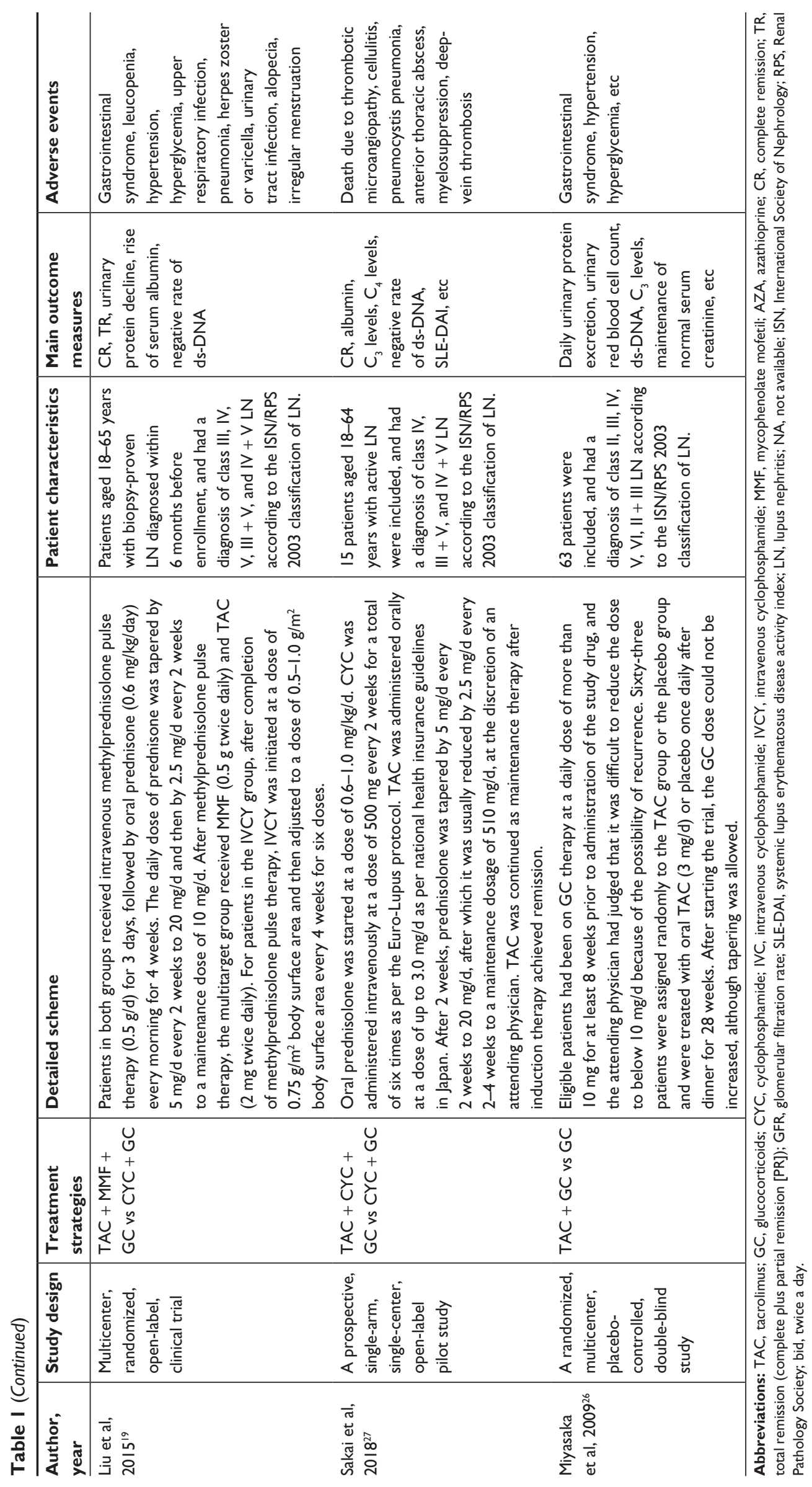


vs CYC + GC, the results indicated that $\mathrm{TAC}+\mathrm{GC}$ group had high values of $\mathrm{CR}(\mathrm{OR}=2.41,95 \% \mathrm{CI}$ : $1.46-3.99$, $P=0.0006$; Figure 1 and Table 2), TR (OR $=4.47,95 \% \mathrm{CI}$ : 2.24-8.95, $P<0.0001$; Figure 1 and Table 2), albumin (WMD $=0.38,95 \%$ CI: $0.10-0.66, P=0.009$; Table 2 ), negative rate of ds-DNA $(\mathrm{OR}=2.51,95 \% \mathrm{CI}: 1.14-5.49, P=0.02$; Figure 1 and Table 2), and low values of proteinuria levels (WMD $=-0.68,95 \% \mathrm{CI}:-1.21$ to $-0.15, P=0.01$; Table 2 ) and SLE-DAI (OR $=-2.00,95 \% \mathrm{CI}:-3.1$ to $-0.85, P=0.0007$; Figure 1 and Table 2) when compared with those in CYC group. However, the differences in urine erythrocyte number, GFR, $\mathrm{C}_{3}$ levels, and $\mathrm{C}_{4}$ levels were not significant between $\mathrm{TAC}+\mathrm{GC}$ group and CYC + GC group (Table 2).

The safety of TAC was also assessed in patients with lupus nephritis. In this meta-analysis, the incidence rates of gastrointestinal syndrome $(\mathrm{OR}=0.30,95 \% \mathrm{CI}$ : $0.12-0.78$, $P=0.01$; Table 3), leucopenia (OR $=0.25,95 \%$ CI: $0.08-0.74$, $P=0.01$; Table 3 ), and irregular menstruation ( $\mathrm{OR}=0.16,95 \%$ CI: $0.05-0.45, P=0.0006$; Table 3 ) in $\mathrm{TAC}+\mathrm{GC}$ group were lower than those in CYC + GC group. The incidence rates of infection, upper respiratory infection, pneumonia, urinary tract infection, alopecia, and liver function disorder in TAC + GC group were lower than those in CYC + GC group, although there were no statistical differences between the groups (Table 3). However, the incidence rates of hypertension, hyperglycemia, herpes zoster or varicella, and increase in blood creatinine levels in TAC + GC group were higher than those in $\mathrm{CYC}+\mathrm{GC}$ group, although there were no statistical differences between the groups (Table 3 ).

\section{Study of the therapeutic regimen of TAC + GC vs MMF + GC}

Three studies ${ }^{18,20,23}$ were included into the meta-analysis to assess the efficacy of TAC in patients with lupus nephritis with the therapeutic regimen of $\mathrm{TAC}+\mathrm{GC}$ vs $\mathrm{MMF}+\mathrm{GC}$, and the results indicated that the differences in $\mathrm{CR}, \mathrm{TR}$, proteinuria levels, and albumin levels between TAC + GC group and $\mathrm{MMF}+\mathrm{GC}$ group were not statistically significant (CR: OR $=0.95,95 \%$ CI: 0.54-1.64, $P=0.84$; TR: $\mathrm{OR}=1.43$, 95\% CI: 0.70-2.91, $P=0.33$; proteinuria levels: $\mathrm{WMD}=0.08$, $95 \% \mathrm{CI}:-0.39$ to $0.55, P=0.75$; albumin: $\mathrm{WMD}=-0.90,95 \%$ CI: -5.77 to $3.96, P=0.72$; Figure 2 and Table 2 ).

The safety of TAC was also assessed in patients with lupus nephritis. In this meta-analysis, the incidence rate of herpes zoster or varicella in TAC $+\mathrm{GC}$ group was lower than that in $\mathrm{MMF}+\mathrm{GC}$ group $(\mathrm{OR}=0.13,95 \% \mathrm{CI}: 0.03-0.53$, $P=0.004$; Table 3). However, the incidence rate of blood creatinine increase in $\mathrm{TAC}+\mathrm{GC}$ group was higher than that in $\mathrm{MMF}+\mathrm{GC}$ group $(\mathrm{OR}=0.13,95 \% \mathrm{CI}: 0.03-0.53$,
$P=0.004$; Table 3). The incidence rates of leucopenia, infection, and serious infection in TAC + GC group were lower than those in MMF + GC group, although there were no statistical differences (Table 3). However, the incidence rate of hyperglycemia in TAC + GC group was higher than that in MMF + GC group, although there was no statistically significant difference (Table 3).

\section{Study of the therapeutic regimen of $\mathrm{TAC}+\mathrm{MMF}+\mathrm{GC}$ vs CYC + GC}

Two studies ${ }^{15,19}$ were included into the meta-analysis to assess the efficacy of TAC in patients with lupus nephritis with the therapeutic regimen of $\mathrm{TAC}+\mathrm{MMF}+\mathrm{GC}$ vs $\mathrm{CYC}+\mathrm{GC}$, the results indicated that the differences of TR, urinary protein decline, and rise of serum albumin between $\mathrm{TAC}+\mathrm{GC}$ group and MMF + GC group were notable (TR: $\mathrm{OR}=3.32,95 \% \mathrm{CI}: 2.08-5.32, P<0.00001$; urinary protein decline: $\mathrm{WMD}=-0.90,95 \% \mathrm{CI}:-1.40$ to $-0.40, P=0.0004$; rise of serum albumin: $\mathrm{WMD}=1.96,95 \% \mathrm{CI}$ : 0.63-3.29, $P=0.004$; Figure 3 and Table 2). The TAC $+\mathrm{MMF}+\mathrm{GC}$ group showed high $\mathrm{CR}$ rate $(\mathrm{OR}=5.13,95 \% \mathrm{CI}: 0.75-35.02$, $P=0.10)$ and negative rate of ds-DNA (OR $=1.67,95 \%$ CI: $1.00-2.79, P=0.05)$, although there were no statistical differences (Figure 3 and Table 2).

The safety of TAC was also assessed in patients with lupus nephritis. In this meta-analysis, the incidence rates of gastrointestinal syndrome $(\mathrm{OR}=0.16,95 \% \mathrm{CI}$ : $0.08-0.35$, $P<0.00001$; Table 3), leucopenia (OR $=0.16,95 \% \mathrm{CI}$ : 0.04-0.59, $P=0.006$; Table 3), and irregular menstruation $(\mathrm{OR}=0.25,95 \% \mathrm{CI}: 0.07-0.93, P=0.04$; Table 3$)$ in $\mathrm{TAC}+\mathrm{MMF}+\mathrm{GC}$ group were lower than those in CYC + $\mathrm{GC}$ group. In this meta-analysis, the incidence rate of hypertension ( $\mathrm{OR}=3.15,95 \% \mathrm{CI}$ : $1.06-9.29, P=0.04$; Table 3 ) in $\mathrm{TAC}+\mathrm{MMF}+\mathrm{GC}$ group was higher than that in $\mathrm{CYC}+$ GC group. The incidence rates of upper respiratory infection, urinary tract infection, and alopecia in $\mathrm{TAC}+\mathrm{MMF}+\mathrm{GC}$ group were lower than those in $\mathrm{CYC}+\mathrm{GC}$ group, although there were no statistical differences (Table 3). However, the incidence rates of hyperglycemia, pneumonia, and herpes zoster or varicella in TAC $+\mathrm{MMF}+\mathrm{GC}$ group were higher than those in $\mathrm{CYC}+\mathrm{GC}$ group, although there were no statistical differences (Table 3).

\section{Discussion}

In the therapeutic regimen of $\mathrm{TAC}+\mathrm{GC}$ vs $\mathrm{CYC}+\mathrm{GC}$, the results indicated that $\mathrm{TAC}+\mathrm{GC}$ group had high values of CR, TR, albumin, and negative rate of ds-DNA, and low values of proteinuria levels and SLE-DAI when compared with those in $\mathrm{CYC}+\mathrm{GC}$ group. In this meta-analysis for 


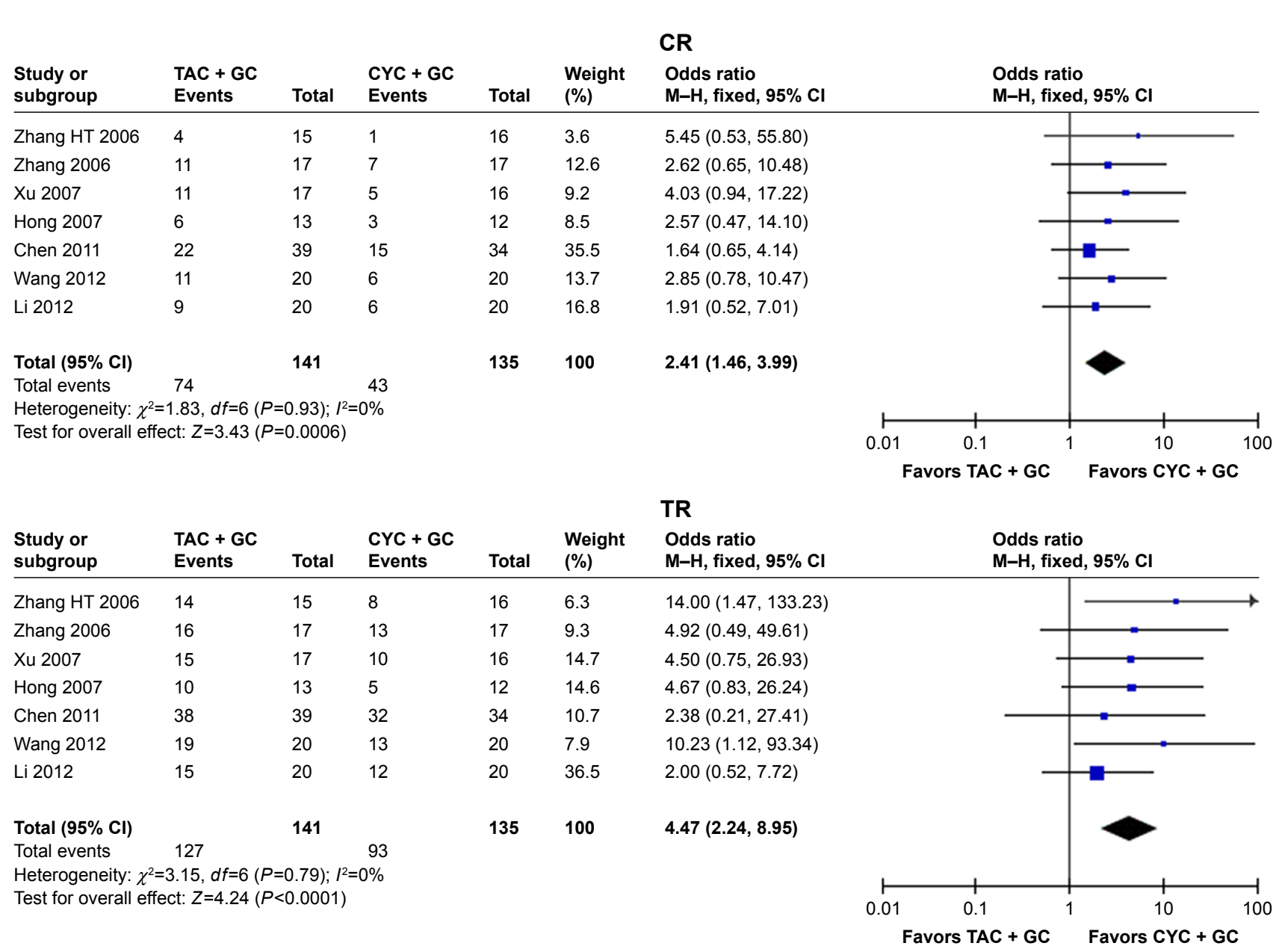

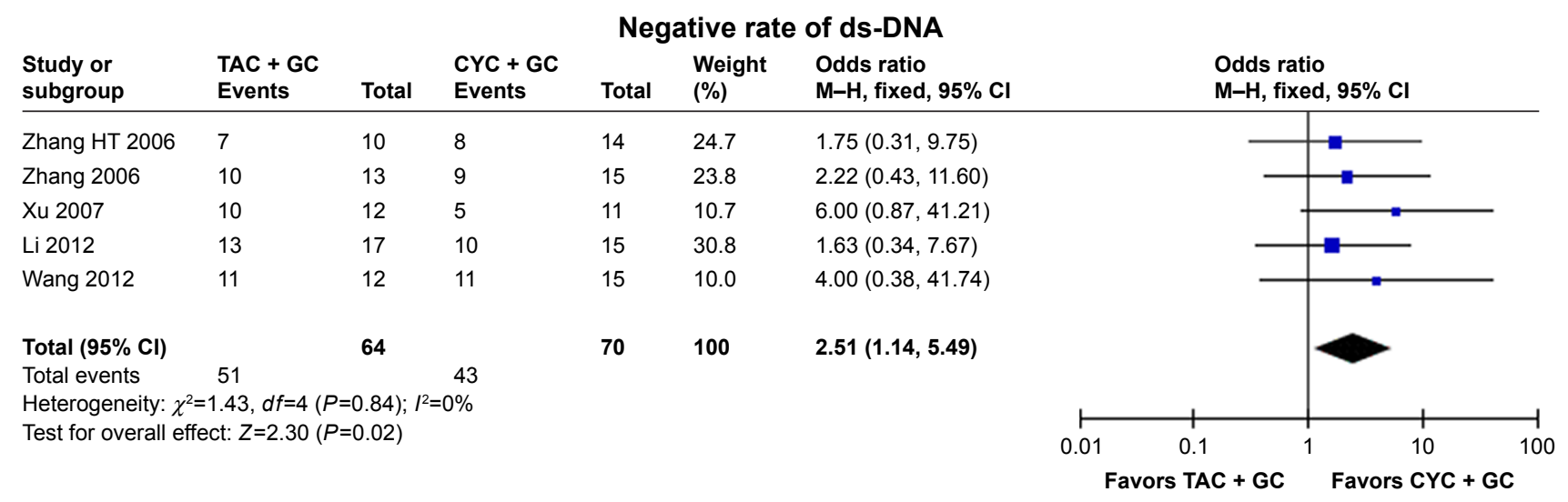

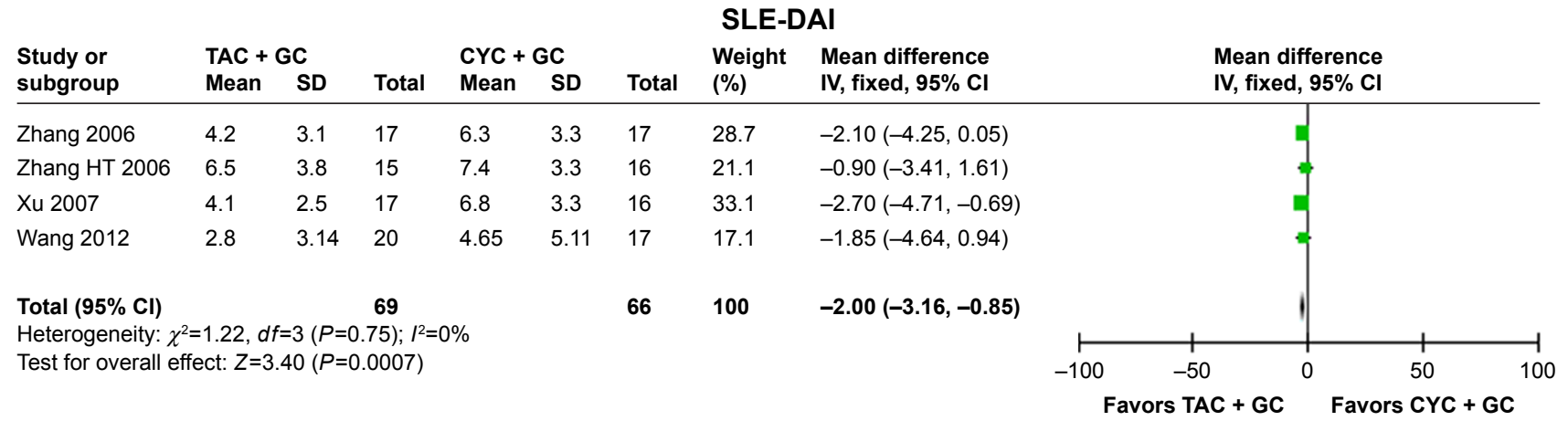

Figure I Assessment of the efficacy of tacrolimus in patients with lupus nephritis (TAC + GC vs CYC + GC).

Abbreviations: TAC, tacrolimus; GC, glucocorticoids; CYC, cyclophosphamide; CR, complete remission; TR, total remission (complete plus partial remission); SLE-DAI, systemic lupus erythematosus disease activity index; $\mathrm{M}-\mathrm{H}$, Mantel-Haenszel. 
Table 2 Meta-analysis of the efficacy of tacrolimus in induction therapy of patients with lupus nephritis

\begin{tabular}{|c|c|c|c|c|c|c|}
\hline Therapeutic regimen & Indicators & $\begin{array}{l}\begin{array}{l}\text { Number } \\
\text { of studies }\end{array} \\
\end{array}$ & $\begin{array}{l}\mathrm{Q} \text { test, } \\
P \text {-value }\end{array}$ & $\begin{array}{l}\text { Model } \\
\text { selected }\end{array}$ & $\begin{array}{l}\text { OR/WMD } \\
(95 \% \mathrm{Cl})\end{array}$ & P-value \\
\hline \multirow[t]{10}{*}{$\mathrm{TAC}+\mathrm{GC}$ vs $\mathrm{CYC}+\mathrm{GC}$} & $\mathrm{CR}$ & 7 & 0.93 & Fixed & $2.4 \mathrm{I}(\mathrm{I} .46,3.99)$ & 0.0006 \\
\hline & $\mathrm{TR}$ & 7 & 0.79 & Fixed & $4.47(2.24,8.95)$ & $<0.0001$ \\
\hline & Proteinuria levels & 4 & 0.41 & Fixed & $-0.68(-1.21,-0.15)$ & 0.01 \\
\hline & Urine erythrocyte number & 2 & 0.93 & Fixed & $-16.96(-55.00,21.07)$ & 0.38 \\
\hline & Albumin & 3 & 0.13 & Fixed & $0.38(0.10,0.66)$ & 0.009 \\
\hline & GFR & 2 & 0.51 & Fixed & $-0.77(-1.66,0.12)$ & 0.09 \\
\hline & Negative rate of ds-DNA & 5 & 0.84 & Fixed & $2.5 \mathrm{I}(1.14,5.49)$ & 0.02 \\
\hline & $\mathrm{C}_{3}$ levels & 3 & 0.41 & Fixed & $0.07(-0.08,0.21)$ & 0.37 \\
\hline & $\mathrm{C}_{4}$ levels & 3 & 0.41 & Fixed & $0.02(-0.04,0.08)$ & 0.52 \\
\hline & SLE-DAI & 4 & 0.75 & Fixed & $-2.00(-3.16,-0.85)$ & 0.0007 \\
\hline \multirow[t]{4}{*}{$\mathrm{TAC}+\mathrm{GC}$ vs $\mathrm{MMF}+\mathrm{GC}$} & $\mathrm{CR}$ & 3 & 0.18 & Fixed & $0.95(0.54,1.64)$ & 0.84 \\
\hline & $\mathrm{TR}$ & 3 & 0.42 & Fixed & I.43 $(0.70,2.91)$ & 0.33 \\
\hline & Proteinuria levels & 2 & 0.09 & Random & $0.08(-0.39,0.55)$ & 0.75 \\
\hline & Albumin & 2 & 0.02 & Random & $-0.90(-5.77,3.96)$ & 0.72 \\
\hline \multirow[t]{5}{*}{$\mathrm{TAC}+\mathrm{MMF}+\mathrm{GC}$ vs $\mathrm{CYC}+\mathrm{GC}$} & CR & 2 & 0.07 & Random & $5.13(0.75,35.02)$ & 0.10 \\
\hline & $\mathrm{TR}$ & 2 & 0.15 & Fixed & $3.32(2.08,5.32)$ & $<0.00001$ \\
\hline & Urinary protein decline & 2 & 0.12 & Fixed & $-0.90(-1.40,-0.40)$ & 0.0004 \\
\hline & Rise of serum albumin & 2 & 0.25 & Fixed & $1.96(0.63,3.29)$ & 0.004 \\
\hline & Negative rate of ds-DNA & 2 & 0.82 & Fixed & $1.67(1.00,2.79)$ & 0.05 \\
\hline
\end{tabular}

Abbreviations: TAC, tacrolimus; GC, glucocorticoids; MMF, mycophenolate mofetil; CYC, cyclophosphamide; CR, complete remission; TR, total remission, complete plus partial remission; SLE-DAI, systemic lupus erythematosus disease activity index; GFR, glomerular filtration rate; WMD, weighted mean difference.

Table 3 Meta-analysis of the safety of tacrolimus in induction therapy of patients with lupus nephritis

\begin{tabular}{|c|c|c|c|c|c|c|}
\hline Therapeutic regimen & Indicators & $\begin{array}{l}\text { Number } \\
\text { of studies }\end{array}$ & $\begin{array}{l}\text { Q test, } \\
\text { P-value }\end{array}$ & $\begin{array}{l}\text { Model } \\
\text { selected }\end{array}$ & $\begin{array}{l}\text { OR } \\
(95 \% \mathrm{CI})\end{array}$ & $P$-value \\
\hline \multirow[t]{13}{*}{$\mathrm{TAC}+\mathrm{GC}$ vs $\mathrm{CYC}+\mathrm{GC}$} & Gastrointestinal syndrome & 4 & 0.63 & Fixed & $0.30(0.12,0.78)$ & 0.01 \\
\hline & Leucopenia & 5 & 0.71 & Fixed & $0.25(0.08,0.74)$ & 0.01 \\
\hline & Hypertension & 3 & 0.93 & Fixed & I.57 (0.4I, 5.9I) & 0.51 \\
\hline & Hyperglycemia & 6 & 0.64 & Fixed & $1.66(0.78,3.54)$ & 0.19 \\
\hline & Infection & 5 & 0.23 & Fixed & $0.77(0.42,1.43)$ & 0.41 \\
\hline & Upper respiratory infection & 2 & 0.45 & Fixed & $0.90(0.90,4.18)$ & 0.89 \\
\hline & Pneumonia & 3 & 0.53 & Fixed & $0.42(0.09,1.93)$ & 0.26 \\
\hline & Herpes zoster or varicella & 4 & 0.54 & Fixed & I.2I $(0.45,3.2 \mathrm{I})$ & $0.7 \mathrm{I}$ \\
\hline & Urinary tract infection & 3 & 0.69 & Fixed & $0.72(0.25,2.05)$ & 0.53 \\
\hline & Alopecia & 3 & 0.33 & Fixed & $0.59(0.19,1.83)$ & 0.36 \\
\hline & Irregular menstruation & 5 & 0.90 & Fixed & $0.16(0.05,0.45)$ & 0.0006 \\
\hline & Blood creatinine increase & 5 & 0.75 & Fixed & I.52 $(0.50,4.60)$ & 0.46 \\
\hline & Liver function disorder & 4 & 0.98 & Fixed & $0.52(0.23,1.20)$ & 0.13 \\
\hline \multirow[t]{6}{*}{$T A C+G C$ vs $M M F+G C$} & Leucopenia & 2 & 0.51 & Fixed & $0.52(0.06,4.12)$ & 0.53 \\
\hline & Hyperglycemia & 3 & 0.88 & Fixed & $2.25(0.69,7.33)$ & 0.18 \\
\hline & Infection & 2 & 0.05 & Random & $0.95(0.06,16.03)$ & 0.97 \\
\hline & Serious infection & 2 & 0.48 & Fixed & $0.43(0.15,1.18)$ & 0.10 \\
\hline & Herpes zoster or varicella & 2 & 0.74 & Fixed & $0.13(0.03,0.53)$ & 0.004 \\
\hline & Blood creatinine increase & 2 & 0.33 & Fixed & I3.54 (I.75, I04.8I) & 0.01 \\
\hline \multirow[t]{10}{*}{$\mathrm{TAC}+\mathrm{MMF}+\mathrm{GC}$ vs $\mathrm{CYC}+\mathrm{GC}$} & Gastrointestinal syndrome & 2 & 0.78 & Fixed & $0.16(0.08,0.35)$ & $<0.00001$ \\
\hline & Leucopenia & 2 & 0.20 & Fixed & $0.16(0.04,0.59)$ & 0.006 \\
\hline & Hypertension & 2 & 0.48 & Fixed & $3.15(1.06,9.29)$ & 0.04 \\
\hline & Hyperglycemia & 2 & 0.61 & Fixed & $1.46(0.43,4.93)$ & 0.54 \\
\hline & Upper respiratory infection & 2 & 0.18 & Fixed & $0.9 \mathrm{I}(0.5 \mathrm{I}, \mathrm{I} .65)$ & 0.76 \\
\hline & Pneumonia & 2 & 0.60 & Fixed & $2.06(0.76,5.6 I)$ & 0.16 \\
\hline & Herpes zoster or varicella & 2 & 0.64 & Fixed & $1.92(0.75,4.91)$ & 0.18 \\
\hline & Urinary tract infection & 2 & 0.75 & Fixed & $0.66(0.18,2.38)$ & 0.52 \\
\hline & Alopecia & 2 & 0.38 & Fixed & $0.52(0.20,1.33)$ & 0.17 \\
\hline & Irregular menstruation & 2 & 0.85 & Fixed & $0.25(0.07,0.93)$ & 0.04 \\
\hline
\end{tabular}

Abbreviations: TAC, tacrolimus; GC, glucocorticoids; MMF, mycophenolate mofetil; CYC, cyclophosphamide. 


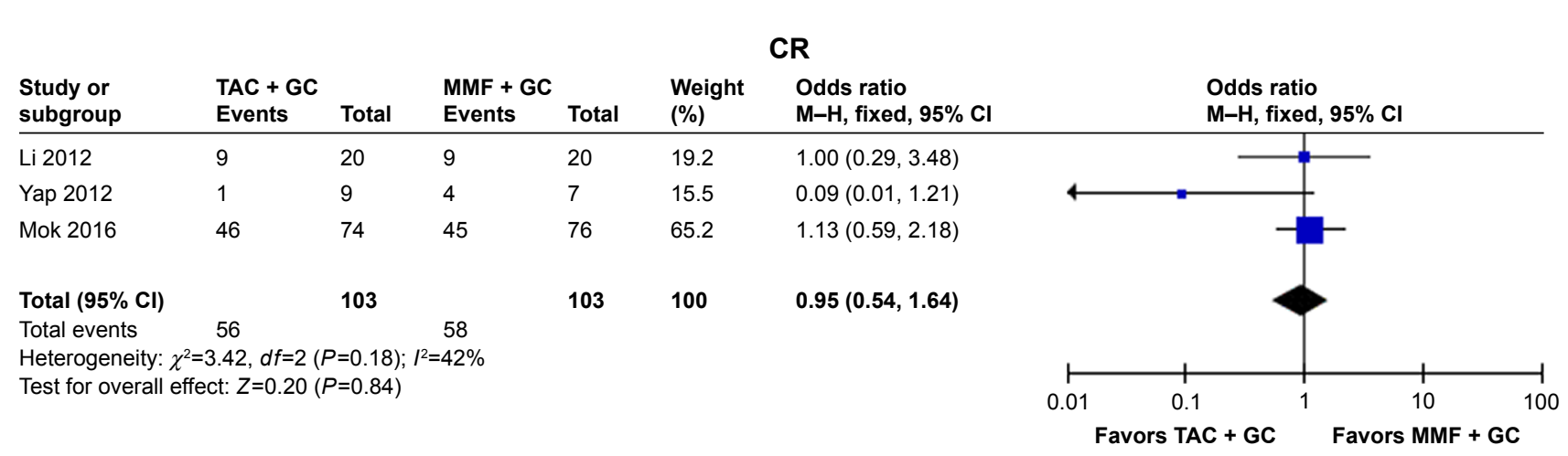

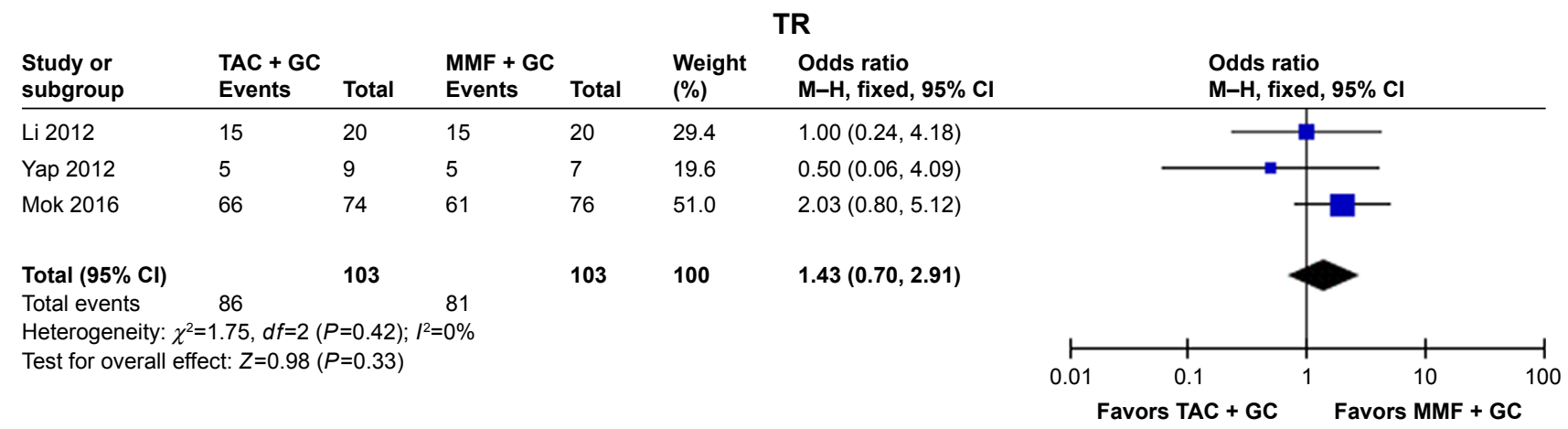

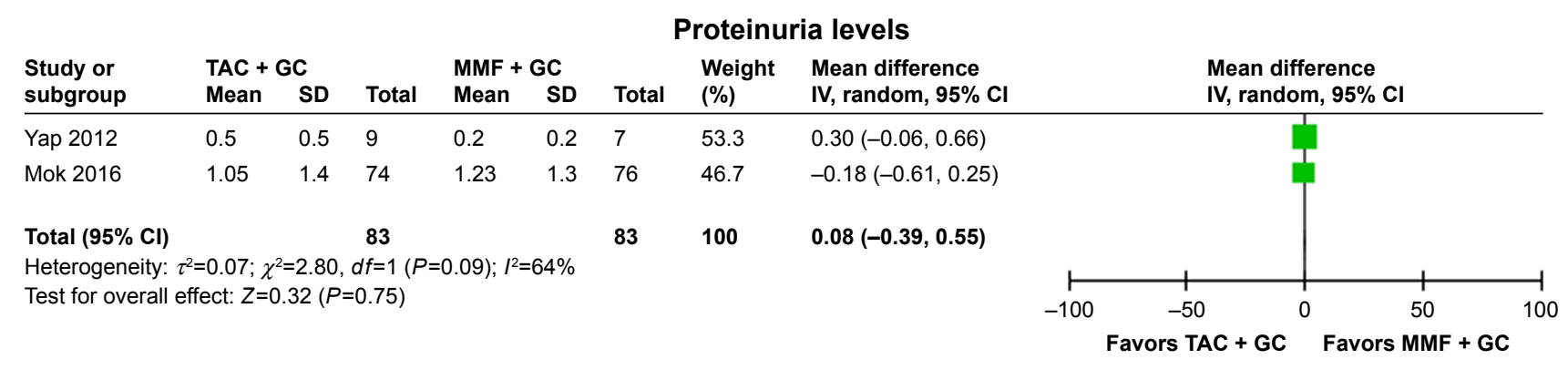

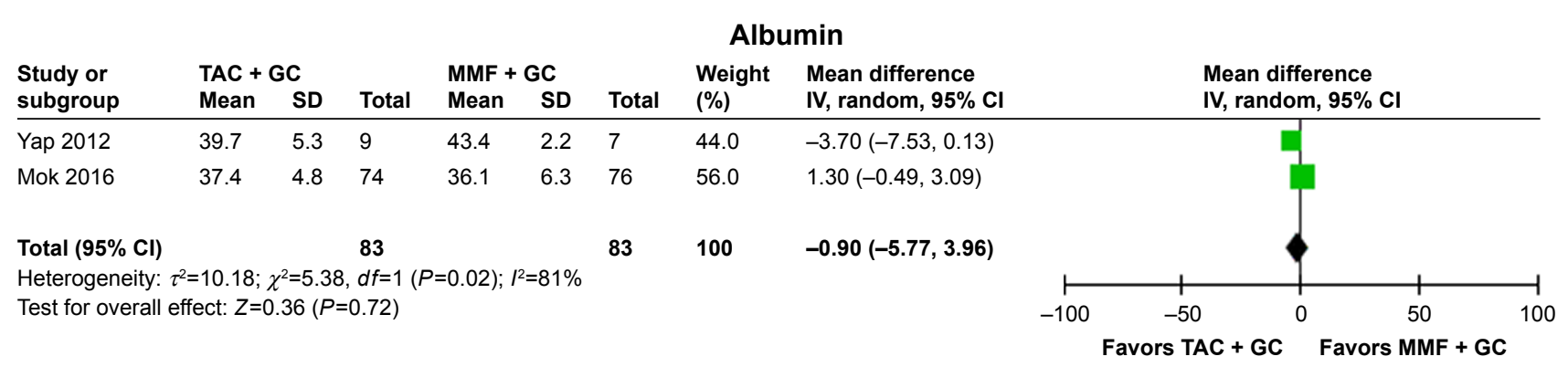

Figure 2 Assessment of the efficacy of tacrolimus in patients with lupus nephritis (TAC + GC vs MMF $+\mathrm{GC}$ ).

Abbreviations: TAC, tacrolimus; GC, glucocorticoids; MMF, mycophenolate mofetil; CR, complete remission; TR, total remission, complete plus partial remission; M-H, Mantel-Haenszel.

adverse events, the TAC + GC treatment showed lower incidence rates of gastrointestinal syndrome, leucopenia, and irregular menstruation than the $\mathrm{CYC}+\mathrm{GC}$ treatment. The $\mathrm{TAC}+\mathrm{GC}$ treatment also showed lower incidence rates of infection, upper respiratory infection, pneumonia, urinary tract infection, alopecia, and liver function disorder when compared with the CYC + GC treatment. However, the TAC + GC treatment showed higher incidence rates of hyperten- sion, hyperglycemia, herpes zoster or varicella, and blood creatinine level increase when compared with the CYC + $\mathrm{GC}$ treatment. In a previous study, Chen et $\mathrm{a}^{28}$ included six studies into the meta-analysis and reported that TAC was superior to CYC in terms of CR rate, TR rate, and anti-dsDNA negative conversion rate. TAC was also associated with less adverse events of gastrointestinal syndrome and amenorrhea than CYC. Kraaij et $\mathrm{al}^{29}$ included five RCTs to investigate 


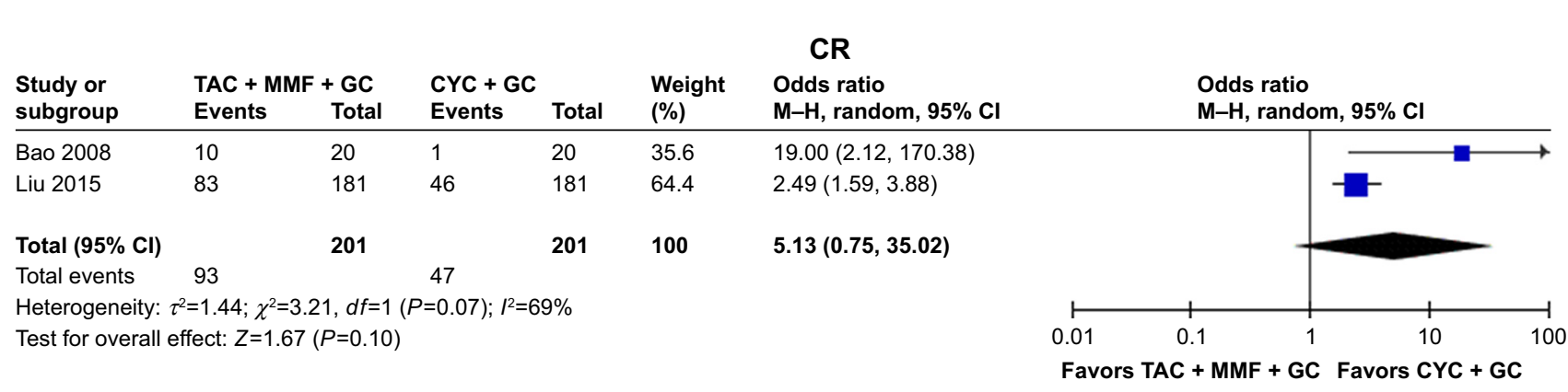

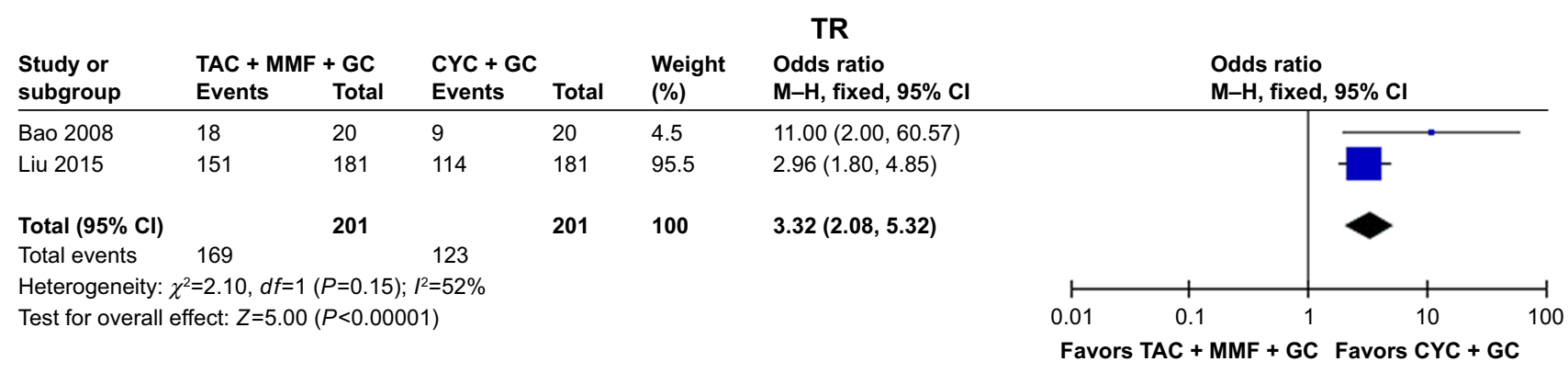

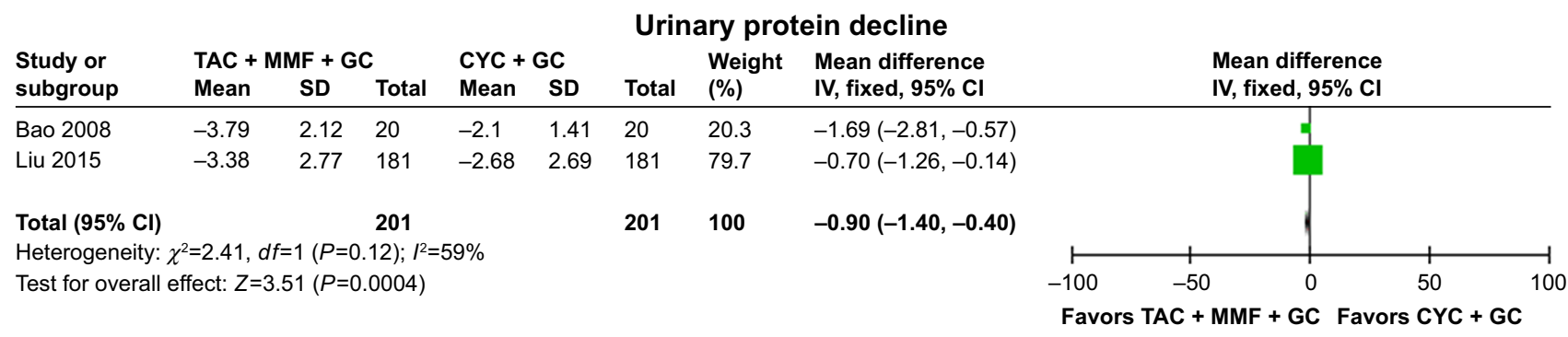

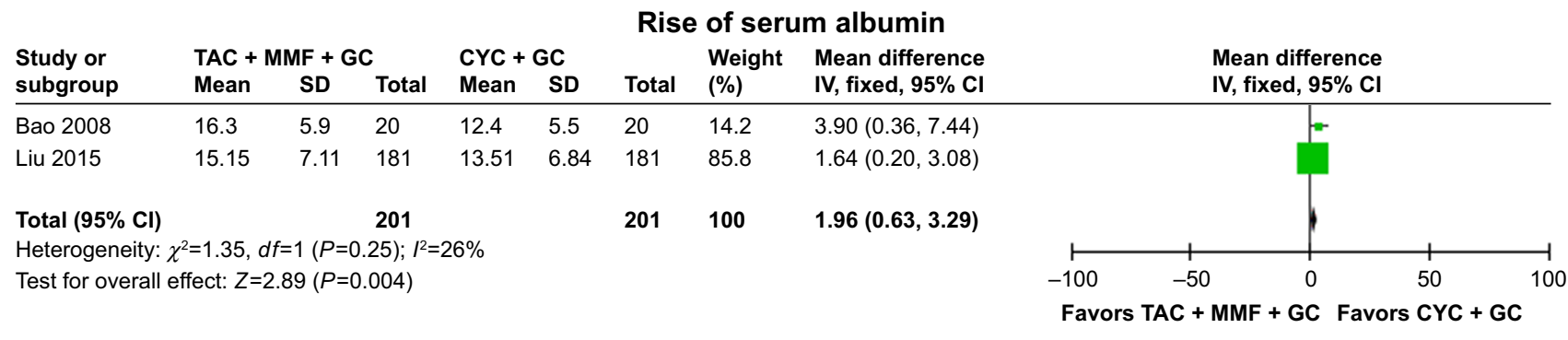

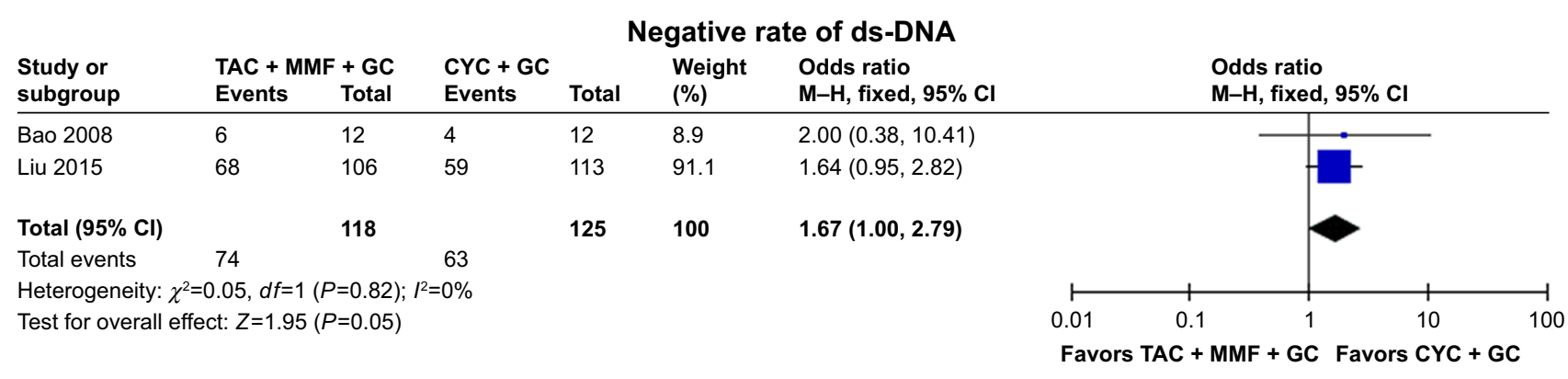

Figure 3 Assessment of the efficacy of tacrolimus in patients with lupus nephritis (TAC + MMF + GC vs CYC + GC).

Abbreviations: TAC, tacrolimus; MMF, mycophenolate mofetil; GC, glucocorticoids; CYC, cyclophosphamide; CR, complete remission; TR, total remission, complete plus partial remission; M-H, Mantel-Haenszel.

TAC in combination with steroids, and reported that TACbased induction treatment led to a significantly higher total renal response. Our meta-analysis included more studies and assessed more indicators than the previous meta-analyses.
In the therapeutic regimen of TAC $+\mathrm{GC}$ vs MMF $+\mathrm{GC}$ of our meta-analysis, the results indicated that the differences in $\mathrm{CR}, \mathrm{TR}$, proteinuria levels, and albumin between TAC + GC group and $\mathrm{MMF}+\mathrm{GC}$ group were not statistically different. 
The incidence rate of herpes zoster or varicella in $\mathrm{TAC}+\mathrm{GC}$ group was lower than that in $\mathrm{MMF}+\mathrm{GC}$ group. However, the incidence rate of blood creatinine increase in TAC + GC group was higher than that in MMF + GC group. In a previous study, Chen et $\mathrm{al}^{28}$ included six studies into the meta-analysis and reported that, in the induction therapy of LN, TAC and MMF were more effective and safer when compared with CYC, but there were no differences of efficacy (CR, TR, proteinuria levels) or safety (major infection, serious infection) between the two treatments. Our meta-analysis included more studies and assessed more indicators than the previous meta-analyses.

We also assessed the multitarget therapy (including the TAC) for induction treatment of lupus nephritis, and reported that the differences in TR, urinary protein decline, and rise of serum albumin between $\mathrm{TAC}+\mathrm{GC}$ group and $\mathrm{MMF}+\mathrm{GC}$ group were notable. The TAC $+\mathrm{MMF}+\mathrm{GC}$ group shows high $\mathrm{CR}$ rate and negative rate of ds-DNA. Calcineurin inhibitors, including TAC and cyclosporine A, inhibit T-cell proliferation by binding to cyclophilin and inhibiting calcineurin phosphatase activity, thus blocking the activation of T-cellspecific transcription factors. ${ }^{30,31} \mathrm{MMF}$, when hydrolyzed to the active drug mycophenolic acid, is a potent inhibitor of the proliferation of $\mathrm{T}$ and $\mathrm{B}$ lymphocytes via reversible inhibition of inosine 5-monophosphate dehydrogenase. ${ }^{30} \mathrm{CYC}$ can selectively deplete the regulatory $\mathrm{T}$ cells and enhance the effector T-cell function. ${ }^{32}$ We speculated that multitarget therapy can well inhibit the proliferation of T and/or B lymphocytes and can obtain good efficacy. The drug doses used in multitarget therapy is much lower than that used for single target therapy, and the adverse reactions may be reduced. In this meta-analysis, the incidence rates of gastrointestinal syndrome, leucopenia, and irregular menstruation in TAC + $\mathrm{MMF}+\mathrm{GC}$ group were lower than that in CYC + GC group. The incidence rates of upper respiratory infection, urinary tract infection, and alopecia in $\mathrm{TAC}+\mathrm{MMF}+\mathrm{GC}$ group was lower than those in CYC + GC group. There was no other meta-analysis that assessed this relationship.

In this systematic review, we also included two studies assessing the efficacy and safety of TAC in induction therapy of patients with lupus nephritis. Miyasaka et $\mathrm{al}^{26}$ conducted a multicenter, double-blind, placebo-controlled study to assess the efficacy and safety of TAC for the treatment of lupus nephritis, and reported that the lupus nephritis disease activity index was decreased in the TAC group and increased in the placebo group. Treatment-related adverse events occurred in $80.0 \%$ of the placebo group and $92.9 \%$ of the TAC group, but the difference was not significant. Sakai et $\mathrm{al}^{27}$ conducted a prospective, single-center, single-arm, open-label pilot study, and reported that multitarget therapy with TAC and CYC can be a good therapeutic option for lupus nephritis.

\section{Conclusion}

In our meta-analysis, we found that TAC is an effective and safe agent for induction therapy of patients with lupus nephritis. However, more studies are needed to confirm these findings in the future.

\section{Acknowledgments}

This study was supported by the Guangzhou Medical Key Discipline Construction Project, the Natural Science Foundation of the Guangdong Province (no 2015A030310386), and Guangdong Medical Science and Technology Research Fund Project (no A2018336). All authors should be regarded as co-first authors in this study.

\section{Disclosure}

The authors report no conflicts of interest in this work.

\section{References}

1. He YY, Yan Y, Zhang HF, et al. Methyl salicylate 2-O- $\beta$-d-lactoside alleviates the pathological progression of pristane-induced systemic lupus erythematosus-like disease in mice via suppression of inflammatory response and signal transduction. Drug Des Devel Ther. 2016;10: 3183-3196.

2. Cogollo E, Silva MA, Isenberg D. Profile of atacicept and its potential in the treatment of systemic lupus erythematosus. Drug Des Devel Ther. 2015;9:1331-1339.

3. Lenert A, Niewold TB, Lenert P. Spotlight on blisibimod and its potential in the treatment of systemic lupus erythematosus: evidence to date. Drug Des Devel Ther. 2017;11:747-757.

4. Hannah J, Casian A, D'Cruz D. Tacrolimus use in lupus nephritis: a systematic review and meta-analysis. Autoimmun Rev. 2016;15(1):93-101.

5. Mok CC. Calcineurin inhibitors in systemic lupus erythematosus. Best Pract Res Clin Rheumatol. 2017;31(3):429-438.

6. Tanaka H, Joh K, Imaizumi T. Treatment of pediatric-onset lupus nephritis: a proposal of optimal therapy. Clin Exp Nephrol. 2017;21(5): 755-763.

7. Takei S, Maeno N, Shigemori M, et al. Clinical features of Japanese children and adolescents with systemic lupus erythematosus: results of 1980-1994 survey. Acta Paediatr Jpn. 1997;39(2):250-256.

8. Bertsias GK, Tektonidou M, Amoura Z, et al. Joint European League against rheumatism and European renal Association-European dialysis and Transplant Association (EULAR/ERA-EDTA) recommendations for the management of adult and paediatric lupus nephritis. Ann Rheum Dis. 2012;71(11):1771-1782.

9. Hogan J, Appel GB. Update on the treatment of lupus nephritis. Curr Opin Nephrol Hypertens. 2013;22(2):224-230.

10. Yap DYH, Chan TM. Lupus nephritis in Asia: clinical features and management. Kidney Dis. 2015;1(2):100-109.

11. Singh JA, Hossain A, Kotb A, Wells GA. Comparative effectiveness of immunosuppressive drugs and corticosteroids for lupus nephritis: a systematic review and network meta-analysis. Syst Rev. 2016; 5(1):155.

12. Mok CC. Therapeutic monitoring of the immuno-modulating drugs in systemic lupus erythematosus. Expert Rev Clin Immunol. 2017;13(1): $35-41$. 
13. Andersson J, Nagy S, Groth CG, Andersson U. Effects of FK506 and cyclosporin A on cytokine production studied in vitro at a single-cell level. Immunology. 1992;75(1):136-142.

14. Singh JA, Hossain A, Kotb A, et al. Treatments for lupus nephritis: a systematic review and network Metaanalysis. J Rheumatol. 2016; 43(10):1801-1815.

15. Bao H, Liu ZH, Xie HL, Hu WX, Zhang HT, Li LS. Successful treatment of class V+IV lupus nephritis with multitarget therapy. J Am Soc Nephrol. 2008;19(10):2001-2010.

16. Chen W, Tang X, Liu Q, et al. Short-term outcomes of induction therapy with tacrolimus versus cyclophosphamide for active lupus nephritis: a multicenter randomized clinical trial. Am J Kidney Dis. 2011;57(2): 235-244.

17. Hong R, Haijin Y, Xianglin W, Cuilan H, Nan C, Hong R. A preliminary study of tacrolimus versus cyclophosphamide in patients with diffuse proliferative lupus nephritis. Nephrol Dial Transplant. 2007; 22(Suppl 6):276.

18. Li X, Ren H, Zhang Q, et al. Mycophenolate mofetil or tacrolimus compared with intravenous cyclophosphamide in the induction treatment for active lupus nephritis. Nephrol Dial Transplant. 2012;27(4):1467-1472.

19. Liu Z, Zhang H, Liu Z, et al. Multitarget therapy for induction treatment of lupus nephritis: a randomized trial. Ann Intern Med. 2015; 162(1):18-26.

20. Mok CC, Ying KY, Yim CW, et al. Tacrolimus versus mycophenolate mofetil for induction therapy of lupus nephritis: a randomised controlled trial and long-term follow-up. Ann Rheum Dis. 2016;75(1):30-36.

21. Wang S, Li X, Qu L, et al. Tacrolimus versus cyclophosphamide as treatment for diffuse proliferative or membranous lupus nephritis: a nonrandomized prospective cohort study. Lupus. 2012;21(9):1025-1035.

22. Xu A, Lu J, Liang Y, et al. Prospective study of tacrolimus in induction trerapy of lupus nephritis. J Sun Yat-Sen Univ. 2007;28(6):683-687.
23. Yap DY, Yu X, Chen XM, et al. Pilot 24 month study to compare mycophenolate mofetil and tacrolimus in the treatment of membranous lupus nephritis with nephrotic syndrome. Nephrology. 2012;17(4): 352-357.

24. Zhang $\mathrm{H}, \mathrm{Hu} \mathrm{W}$, Xie $\mathrm{H}$, et al. Tacrolimus versus intravenous cyclophosphamide in the induction therapy of diffuse proliferative lupus nephritis. J Nephrol Dialy Transplant. 2006;15(6):501-506.

25. Zhang $\mathrm{H}, \mathrm{Hu} \mathrm{W}$, Xie H, et al. Randomized controlled trial of tacrolimus versus intravenous cyclophosphamide in the induction trerapy of class V plus IV lupus nephritis. J Nephrol Dialy Transplant. 2006; 15(6):508-514.

26. Miyasaka N, Kawai S, Hashimoto H. Efficacy and safety of tacrolimus for lupus nephritis: a placebo-controlled double-blind multicenter study. Mod Rheumatol. 2009;19(6):606-615.

27. Sakai R, Kurasawa T, Nishi E, et al. Efficacy and safety of multitarget therapy with cyclophosphamide and tacrolimus for lupus nephritis: a prospective, single-arm, single-centre, open label pilot study in Japan. Lupus. 2018;27(2):273-282.

28. Chen Y, Sun J, Zou K, Yang Y, Liu G. Treatment for lupus nephritis: an overview of systematic reviews and meta-analyses. Rheumatol Int. 2017;37(7):1089-1099.

29. Kraaij T, Bredewold OW, Trompet S, et al. TAC-TIC use of tacrolimusbased regimens in lupus nephritis. Lupus Sci Med. 2016;3(1):e000169.

30. Jesus D, Rodrigues M, da Silva JAP, Inês L. Multitarget therapy of mycophenolate mofetil and cyclosporine A for induction treatment of refractory lupus nephritis. Lupus. 2018;27(8):1358-1362.

31. Bao J, Gao S, Weng Y, Zhu J, Ye H, Zhang X. Clinical efficacy of tacrolimus for treating myasthenia gravis and its influence on lymphocyte subsets. Rev Neurol. 2019;175(1-2):65-72.

32. Madondo MT, Quinn M, Plebanski M. Low dose cyclophosphamide mechanisms of T cell modulation. Cancer Treat Rev. 2016;42:3-9.

\section{Publish your work in this journal}

Drug Design, Development and Therapy is an international, peerreviewed open-access journal that spans the spectrum of drug design and development through to clinical applications. Clinical outcomes, patient safety, and programs for the development and effective, safe, and sustained use of medicines are the features of the journal, which

\section{Dovepress}

has also been accepted for indexing on PubMed Central. The manuscript management system is completely online and includes a very quick and fair peer-review system, which is all easy to use. Visit http://www.dovepress.com/testimonials.php to read real quotes from published authors.

Submit your manuscript here: http://www.dovepress.com/drug-design-development-and-therapy-journal 